\title{
A multidisciplinary approach to the functional abnormalities of the migrainous brain and non-invasive interventions to treat them
}

\author{
Alessandro Viganò ${ }^{1,2,3^{*}}$, Volodymyr B Bogdanov ${ }^{4}$, Jean Schoenen ${ }^{1,5}$ \\ From The European Headache and Migraine Trust International Congress \\ London, UK. 20-23 September 2012
}

\section{Background}

Migraine is characterized pathophysiologically by an interictal habituation deficit of information processing, responsible for cortical hyperresponsiveness, which normalizes during attacks [1]. Furthermore, descending pain control systems (DPCSs) can be impaired in episodic and chronic migraine $[3,4]$. Noninvasive neuromodulation of the cerebral cortex may be effective in migraine prophylaxis [2] including, in chronic migraine, modulation of the dorsolateral prefrontal cortex (DLPFC) that is part of the DPCSs [5].

\section{Aims}

To identify targets and neuromodulation interventions for migraine treatment by exploring the role of DLPFC in heterotopic noxious analgesia and by using transcranial magnetic (rTMS) and direct current stimulation (tDCS).

\section{Methods}

To this purpose, we performed the following studies:

1) we studied the modification of visual cortex (VC) responsiveness, as assessed by visual evoked potentials (VEPs), induced by excitatory intermittent theta-burst rTMS (i-TBS) [6] or anodal (i.e. excitatory) tDCS (AtDCS) [7] in healthy volunteers (HV) and in episodic migraineurs (EM)

2) we used AtDCS on VC (twice/week for 8 weeks) in a pilot study of migraine prevention.

3) we used fMRI to explore the role of DLPFC in heterotopic noxious analgesia induced by painful cold in EM during and between attacks.

\section{Results}

i-TBS induced a sustained increase of 1 st block VEP amplitude and habituation in HV $(n=13)$. AtDCS increased habituation in HV $(n=11)$ and EM $(n=12)$.

In the prophylactic trial $(\mathrm{n}=7)$, AtDCS reduced significantly migraine frequency $(-40 \%)$, and attack duration $(-43.25 \%)$.

In migraineurs, interictally, cold-induced analgesia, which was related to baseline autonomic arousal, was proportional to cold-induced BOLD responses in the DLPFC. During an attack, BOLD responses induced in the premotor cortex by cold application on the foot were also significantly increased.

\section{Conclusions}

Excitatory neuromodulation (both i-TBS or tDCS) of the visual cortex in HV induces changes in cortical responsiveness that should be able to normalize the interictal abnormalities found in migraineurs. Our pilot therapeutic study suggests that excitatory anodal tDCS could have a preventive anti-migraine effect. Finally, the impaired descending analgesia that characterizes migraine could be amenable to AtDCS or i-TBS neuromodulation targeting the DLPFC and premotor cortices.

\footnotetext{
Author details

${ }^{1}$ Headache Research Unit. Dept of Neurology, University of Liège, Belgium. ${ }^{2}$ Brain Morphometry and Dynamics Lab., Dept of Anatomy, Histology, Forensic Medicine and Orthopaedics, Sapienza University of Rome, Italy. ${ }^{3}$ Neurology A. Dept of Neurology and Psichiatry. Sapienza University of Rome, Italy. ${ }^{4}$ Department of Neurology, University of Utah, Salt Lake City, USA. ${ }^{5}$ Giga-Neurosciences, University of Liège, Belgium.
} 


\section{References}

1. Coppola G, Pierelli F, Schoenen J: Is the cerebral cortex hyperexcitable or hyperresponsive in migraine? Cephalalgia 2007, 27:1429-1439.

2. Fumal A, Coppola G, Bohotin V, Gérardy PY, Seidel L, Donneau AF, Vandenheede M, Maertens de Noordhout A: Induction of long-lasting changes of visual cortex excitability by five Schoenen J. daily sessions of repetitive transcranial magnetic stimulation (rTMS) in healthy volunteers and migraine patients. Cephalalgia 2006, 26(2):143-9.

3. Sandrini G, Rossi P, Milanov I, Serrao M, Cecchini AP, Nappi G: Abnormal modulatory influence of diffuse noxious inhibitory controls in migraine and chronic tension-type headache patients. Cephalalgia 2006, 26:782-789.

4. de Tommaso M, Sardaro M, Pecoraro C, Di Fruscolo O, Serpino C, Lamberti P, Livrea P: Effects of the remote C fibres stimulation induced by capsaicin on the blink reflex in chronic migraine. Cephalalgia 2007.

5. Brighina F, Piazza A, Vitello G: rTMS of prefrontal cortex in the treatment of chronic migraine: a pilot study. Journal of the Neurological Sciences 2004, 67-71.

6. Ying-Zu Huang, Mark J Edwards, Elisabeth Rounis, Kailash P Bhatia, John C Rothwell: Theta Burst Stimulation Report of the Human Motor Cortex Neuron. 2005, 45:201-206.

7. Lefaucheur JP: Methods of therapeutic cortical stimulation. Clinical Neurophysiology 2009, 39:1-14.

doi:10.1186/1129-2377-14-S1-15

Cite this article as: Viganò et al:: A multidisciplinary approach to the functional abnormalities of the migrainous brain and non-invasive interventions to treat them. The Journal of Headache and Pain 2013 14(Suppl 1):15.

\section{Submit your manuscript to a SpringerOpen ${ }^{\mathcal{O}}$ journal and benefit from:}

- Convenient online submission

- Rigorous peer review

- Immediate publication on acceptance

- Open access: articles freely available online

- High visibility within the field

- Retaining the copyright to your article

Submit your next manuscript at $\gg$ springeropen.com 